\title{
Are Campus Bicycle Sharing Schemes Useful? An Analysis with Kyoto University Data
}

\author{
Tomoki Nishigaki ${ }^{1}$, Jan-Dirk Schmöcker ${ }^{1}$, Toshiyuki Nakamura ${ }^{2}$ \\ and Nobuhiro $\mathrm{Uno}^{3}$ \\ ${ }^{1}$ Department of Urban Management, Graduate School of Engineering, \\ Kyoto University, Japan \\ Email: \{nishigaki, Schmoecker\}@trans.kuciv.kyoto-u.ac.jp \\ ${ }^{2}$ Institute of Innovation for Future Society, Nagoya University, Nagoya \\ Email: tnakamura@mirai.nagoya-u.ac.jp \\ ${ }^{3}$ Department of Civil and Earth Resources Engineering, \\ Graduate School of Engineering, Kyoto University, Japan \\ ${ }^{4}$ Email: uno@trans.kuciv.kyoto-u.ac.jp
}

\begin{abstract}
To encourage good accessibility between university facilities as well as to reduce the amount of parked bicycles, some universities have introduced bicycle sharing schemes. One example is Kyoto University where a scheme has been introduced in 2014 with mixed success. In this paper, we discuss characteristics of the users in order to derive some general conclusions on how shared bicycle schemes can be more successful. First, we analyze individual usage records. Through cluster analysis we could divide users into 6 groups based on time and frequency of usage as well as how often bicycle usage exceeds the allowed time. We observe distinctive differences in trip purposes and travel patterns between these groups. Second, we conducted a questionnaire analysis to obtain a deeper understanding regarding the difference between users and non-users. We find that "innovativeness" to some degree explains usage. Further, the results highlight the importance of convenience and that participants do not care sufficiently about some of the usage rules. The findings also highlight a conflict in that the scheme indirectly supports those coming by motorized transport to campus.
\end{abstract}

Keywords: bicycle sharing, university campus, survey, regression analysis

\section{Introduction}

An increasing number of cites recently introduce bicycle sharing systems, in order to promote health consciousness and awareness of environmental problems. The rationale for campus and workplace bicycle sharing schemes for companies with large grounds also might include such arguments but are often driven more by a motivation to improve accessibility of facilities that students or workers have to access (within short time) but that take time to reach walking. In addition, sharing bicycles schemes can reduce the amount of parked bicycles for which there might be limited space. This is particularly a problem in some Japanese cities where cycling is popular and purchasing used bicycles is cheap so that people tend to own multiple bicycles and leave them around stations or on campus for "last mile" issues or for errands during the day. The hope is that bicycle sharing schemes will reduce the need for such behavior and therefore free up parking spaces and reduce the number of illegally parked bicycles.

However, there are few successful cases of campus bicycle sharing. Clearly spatial characteristics where the scheme has been introduced have a strong influence on the uptake of a bicycle sharing system [1]. Spatial characteristics are further connected to 
adequate arrangement of parking facilities and usage rules and fares. To design these in turn a good understanding of user needs is required.

In addition to this authors have argued that especially in Japan, riding a bicycle is more similar to walking than to riding a car [2]. Because of this, almost all Japanese have their own bicycles even if they seldom use it. This also often prevents the success of shared bicycle schemes in Japan. One key to the success of cycling policies in northern Europe is the coordinated implementation of a "multi-faceted, self-reinforcing set of policies". Since their policies are sensitive to the very different needs of different social groups, they also succeed in making cycling accessible to a large population group [3].

Considering this background, we aim to understand who uses the shared bicycles and for what type of trips. Our purpose is to know the characteristics of a bicycle sharing scheme that make it attractive to users and sustainable in the long run. We focus on the scheme at Kyoto University where we have usage data over one year. We analyse for which users shared bicycles are attractive and discuss problems of the scheme that led to its suspension for over a year. From this we aim to derive some general conclusions how shared bicycle schemes can be more successful.

The bicycle sharing scheme at Kyoto University is called "COGOO". This scheme is adopted in six Japanese universities, namely, Yokohama National University, Chiba University, Hitotsubashi University, Osaka University, Kyushu University and Kyoto University. In all six cases, users can rent the bicycles without charge after registration. Other aspects of the usage rules differ though between the schemes. Whereas in Osaka University the scheme can be used $120 \mathrm{~min}$ without charge, in Yokohama National University and Chiba University the maximum allowed rental duration 30min. In Yokohama National University, if users break the rule, they are imposed a penalty fee (3000 Japanese Yen). To consider is also that the campus locations vary significantly. Whereas Yokohama National University campus is in the city center, the Fukuoka campus is far from the city and students or staffs need to use motorized transport to reach the campus.

The COGOO scheme was launched at Kyoto University in March 2014. The main campus of Kyoto University is located inside the city but it has a wide campus area where it is convenient for students and staffs to ride a bicycle if they need to attend lectures or academic facilities in other parts of the campus. Further, different to the other COGOO cases, some major roads divide the campus of Kyoto University into four parts. This may promote users taking out the bicycles from the university campus for a range of purposes.

As we will describe in more detail in the next section, so far few students and university staffs know and use the system. Furthermore, a number of people have been using the system inappropriate. For example, they have not been properly returning the bicycle or exceeding the allowed rental duration time so that, in connection with some technical issues, COGOO has been suspended since April 2015. For the 13 month in which the system has been in operation, we have individual usage records.

In the following we firstly analyze these individual usage records. Through cluster analysis we find that we can divide the users into six groups based on attributes such as time of usage, frequency of usage as well their origins and destinations. Second, we conducted a questionnaire analysis in order to obtain a deeper understanding regarding the difference between users and not-users. We show that attitudinal factors as well as activities of students outside class are important for demand prediction.

\section{Previous Studies}

There is by now a substantial body of literature about cycling and bicycle sharing from around the world. One important aspect in the discussion has always been safety. In the Unitied States, with bicycling accounting for $2 \%$ of all passenger miles, the fatality rate per passenger mile traveled is 10 times higher for bicyclists than for auto occupants, 
which obviously discourages many potential bicyclists [3]. In Japan as well as European countries such as The Netherlands and Germany fatality rates are much lower [4]. One reason might be that the Netherlands and Germany have long recognized the importance of pedestrian and bicyclist safety. Pucher writes that over two decades, these countries have undertaken a wide range of measures to improve safety. For example, better facilities for walking and bicycling; urban design sensitive to the needs of non-motorists; traffic calming of residential neighborhoods; restrictions on motor vehicle use in cities; rigorous traffic education of both motorists and non-motorists; and strict enforcement of traffic regulations protecting pedestrians and bicyclists.

Goodman et al suggests that bicycle sharing systems may help normalizing the image of cycling, and reduce perceptions that cycling is 'risky' or 'only for sporty people' [5]. They compared the use of specialist cycling clothing between users of the London bicycle sharing system (LBSS) and cyclists using personal bicycles. They observed people on bicycles at randomly selected locations across central and inner London and found that LBSS users were much less likely to wear helmets, high-visibility clothes and sports clothes. They found that in total 79\% of LBSS users wore none of these types of specialist cycling clothing as compared to only $30 \%$ of personal bicycle cyclists and the differences was significant for both male and female.

In Minnesota a survey analysis about the "Nice Ride" bike share system has been carried out [6]. The authors observed a statistically significant relationship between station trip activity and the number of food-related businesses and job accessibility within a bike share station area. Business owners and managers corroborated these findings by revealing general positive attitudes toward Nice Ride users as customers, although interviewees were ambivalent when asked if they would trade parking or sidewalk cafe space for a Nice Ride station. The user survey revealed that respondents use bike sharing to go to cafes, restaurants, grocery stores, concerts, bars, and the like, and they spend modest amounts of money on these trips. The availability of Nice Ride stations mainly supports mode shifts (e.g., people who choose to bike rather than drive or walk) but it also may induce some new trips.

A survey analysis from Dublin showed that their higher income individuals use the cycle sharing scheme there predominantly [7]. The report shows that the cycle sharing scheme has a different functionality during the peak and off-peak and has been indirectly successful at improving driver awareness towards cyclists.

Others mention that the operators should notice that the most significant factors contributing to higher general satisfaction is user's perception on bike availability and operation time, thus operators should devote more effort to ensure service quality of these two items [8]. To some degree also in line with this a recent review paper mentions that convenience is the major motivator for bike share use [9]. The author discusses that in a range of countries, it has been found that just under $50 \%$ of bike share members use the system less than once a month. Shaheen et al., mentioned that we could categorize evolution of bike sharing into three generations: 1) White Bikes (or Free Bike Systems); 2) Coin-Deposit Systems; and 3) IT-Based Systems [10]. In addition to this, they then propose a fourth generation, "Demand-Responsive, Multi-Modal Systems." A range of existing bike sharing business models (e.g., advertising) and lessons learned are discussed including: 1) bicycle theft and vandalism; 2) bicycle redistribution; 3) information systems (e.g., real-time information); 4) insurance and liability concerns; and 5) prelaunch considerations. In addition to this, they also mentioned that ongoing growth of bicycle-sharing, obstacles and uncertainty remain, including: future demand; safety; sustainability of business models; limited cycling infrastructure; challenges to integrating with public transportation systems; technology costs; and user convenience (e.g., limited height adjustment on bicycles, lack of cargo space, and exposure to weather conditions). In this way, bicycle sharing schemes still have many obstacles and we understand feature of the system somehow. 
There have been less studies on predicting demand for cycle sharing. [11] sets out a method for estimating the bicycle-sharing demand with an approach that allows to georeference the demand, considering the characteristics of the city and of the trips. They obtain the proportion of bike sharing users by considering a range of case studies and considering trip characteristics such as travel time between traffic zones and physical city characteristics such as slopes. The paper further distinguishes demand for three typical user groups: commuters, recreational/errand riders and tourists. Moreover, they test their approach with a small case study.

From this international literature, we can conclude that there are some common, but also some region specific problems to promote shared cycling. There is also Japanese literature on cycle sharing, besides the relative minor role of bicycle sharing. [12] mentions that it is difficult to introduce a bicycle sharing schemes in Japan, where users have comparatively cheap access to new or used bicycles. In Japan, Japanese can often buy a basic second hand bicycle for around Yen 5,000 (about US\$50).

Ieda et al., constructed a model for estimating how bike sharing system users decide their parking place through a prior survey analysis [13]. They found that besides distance, fare and time the tendency to park at illegal spaces has an influence. That is, users who have parked in the past illegally are likely to continue doing so. This has also been the topic of [14], who conducted a survey analysis discussing illegally parked bicycles in Okayama prefecture, Japan. They found that the reason why there were many illegally parked bicycles around a shopping area was that there were not enough space for parking. [15] also studied the problem of illegal parking and found that persuasion was effective for giving up parking bicycles illegally, though the effect appears not to last for longer time. [16] looked at bicycle sharing again with a very different perspective. They considered factors making bicycle sharing more attractive and discussed the importance of visual attractiveness including a good logo.

There are further two studies published in Japanese focusing on cycle sharing at Japanese universities. [17] uses the COGOO data from Yokohama University. They report that, on average, students or staffs of Yokohama National University used each COGOO bicycle more than two times per day. Furthermore, $90 \%$ of the rentals last less than 15 minutes. We will discuss in the following that the usage pattern is quite different at Kyoto University. [18] report a result of an experiment with a rental cycle system at Kyushu University. They mention that students of Kyushu University use the system not primarily for commuting between lectures or other on-campus facilities inside the university but mostly for going out of the campus. We will show that our results from Kyoto University are in line with this and aim to understand in more detail some of the usage aspects.

\section{Study Area and Data}

At Kyoto University, it is free to enter the campus by bicycle and to park these on the campus. Students and staffs do not need to register. Visitors to the campus will though soon observe that there are many bicycles parked outside the designated areas. Mainly to tackle this problem, Kyoto University introduced the COGOO system.

There are 10 cycle ports in the main campus of Kyoto University as illustrated in Figure 1. Seven of these were installed since the opening of COGOO and three (C4, M1 and M2) were added from October 2014. Initially, between March and September 2014 there were 28 COGOO bicycles available which increased to 100 bicycles from October 2014 to March 2015.

Students and staff who have registered for COGOO can use a bicycle for up to one hour unlimited number of times free of charge. Using COGOO for more than one hour, but less than two hours has though no consequences for the user. The 
published rules stipulate that users who do not return a bicycle within 2 hours to any of the docking stations will be banned from using the scheme. However, our data analysis indicates that even if users violate the rule, operators did not inflict this punishment on them. This is possibly one of the causes for the illegal usage rate reaching up to about $40 \%$. Table 1 shows a summary of COGOO data and the basic analysis. We note that for some users who withdrew from the system fast, some data, such as ID, faculty and gender were not available.

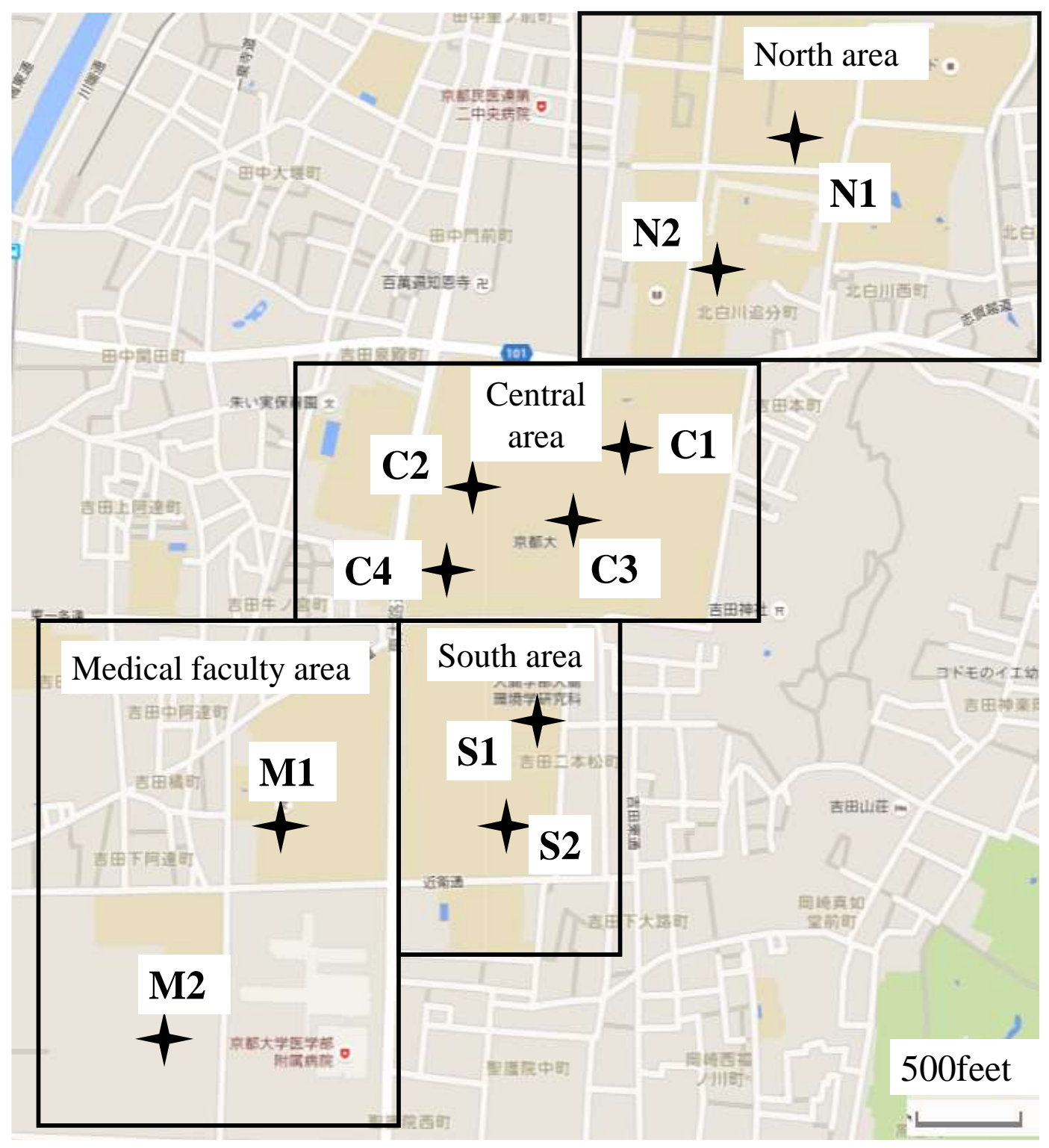

Figure 1. Map of Kyoto-university and Port 
Table 1. Kyoto University COGOO Scheme and Available Data

\begin{tabular}{|c|c|}
\hline Term & $2014 / 3 / 13^{\sim} 2015 / 3 / 31$ \\
\hline Users & 1281 \\
\hline Trips & 14028 \\
\hline Allowed usage time & up to 1 hour \\
\hline Number of ports & see Figure 1 \\
\hline Location of docking ports & $\begin{array}{c}\text { ID, faculty, grade, gender, registration date, } \\
\text { origin port, destination port, beginning time, return time }\end{array}$ \\
\hline Data contents & $38.30 \%$ \\
\hline $\begin{array}{c}\text { Illegal usage rate } \\
\text { (rental > 1h) }\end{array}$ & 0.84 \\
\hline $\begin{array}{c}\text { Usage rate } \\
\text { per bicycle and day }\end{array}$ & \\
\hline
\end{tabular}

\section{Descriptive Data Analysis}

Figure 2 shows the accumulation of registered number of users as well as the number of active users per month. The figure illustrates that the number of new users was increasing gradually. However, number of active users per month did not increase. This suggests that the number of people using COGOO only a few times and then dropping out is significant.

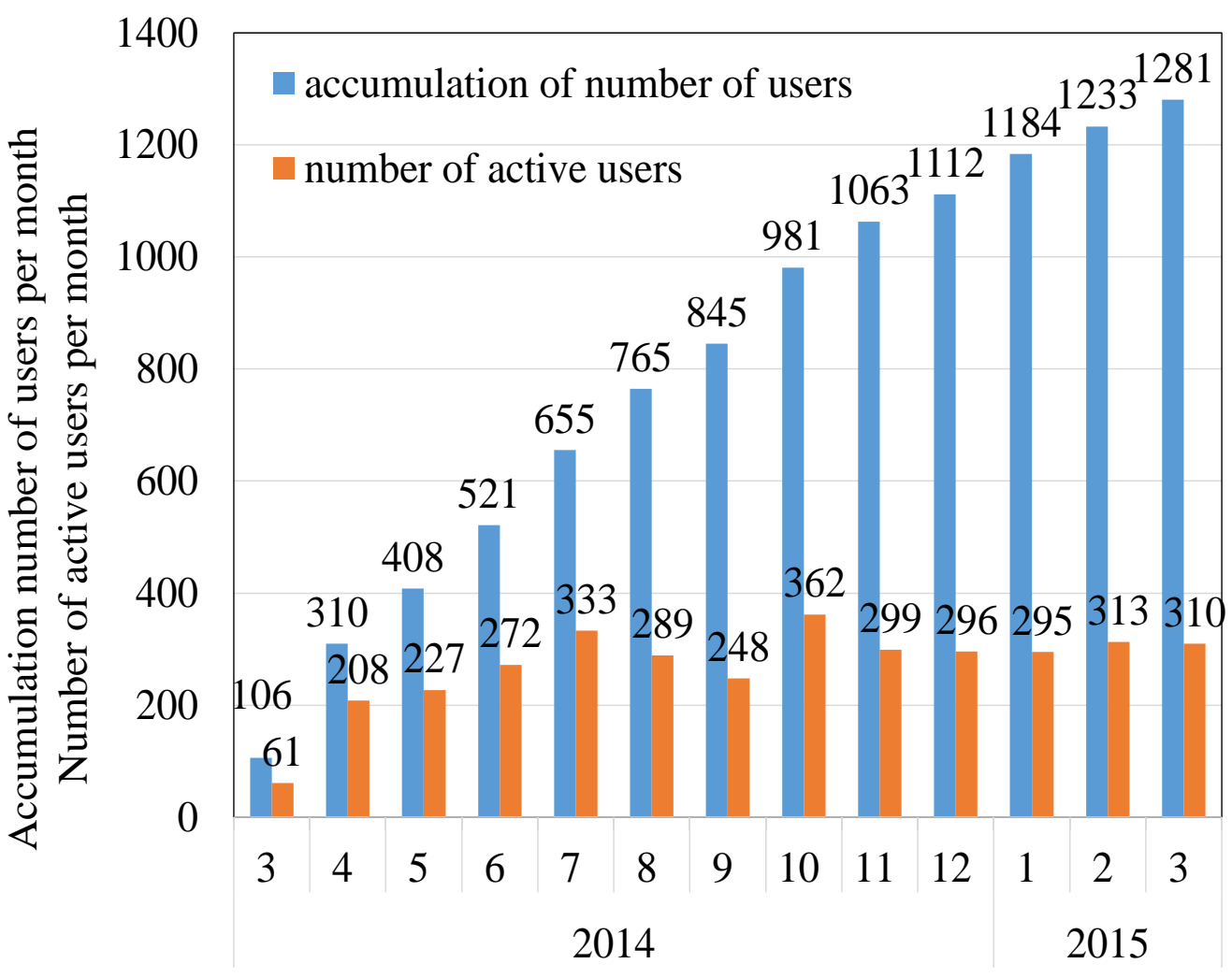

Figure 2. Number of Users 
We further analyzed the usage per day each month as shown in the next two figures. Figure 3 is for weekdays and Figure 4 shows the usage on holidays. In this study, holiday means holiday in academic calendar of Kyoto University. We observe that the main usage is on weekdays as expected. In addition to this, in August and September the usage is low since this is the summer vacation period. [19] further the trends in usage patterns of individuals over the 13 months is analysed. The paper discusses that though a majority of users have stable usage patterns the proportion of users turning reducing their usage increases over time.

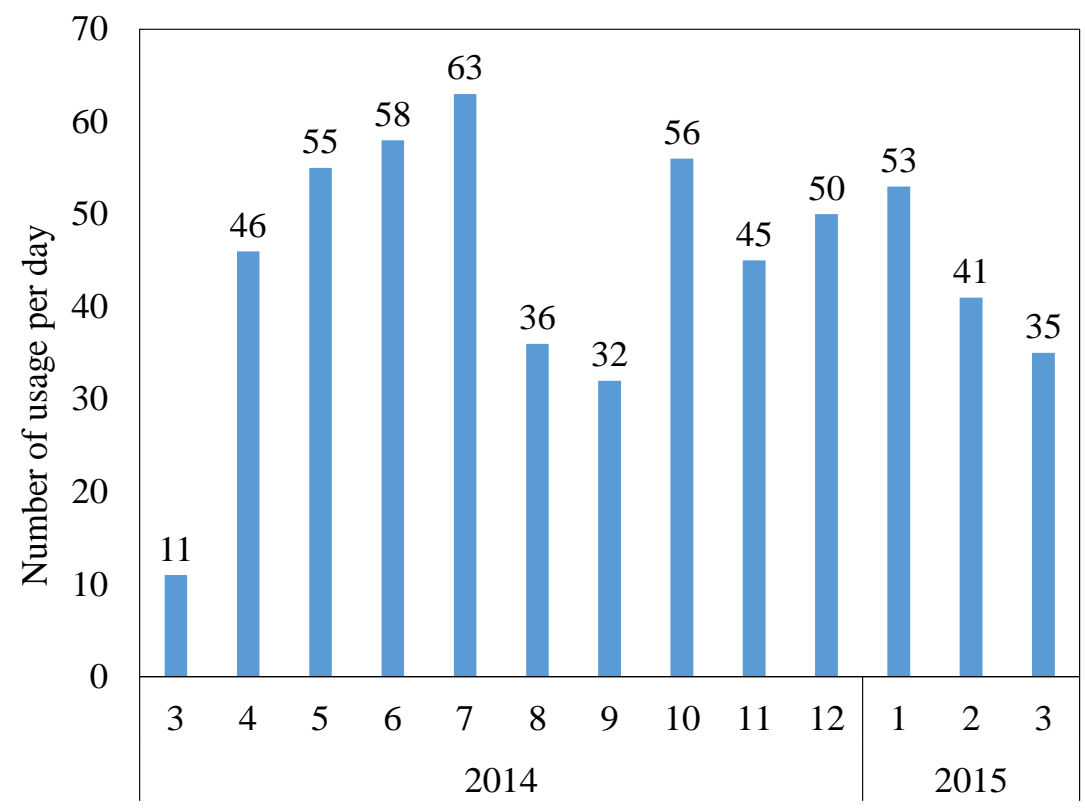

Figure 3. Average Daily Usage (Weekday)

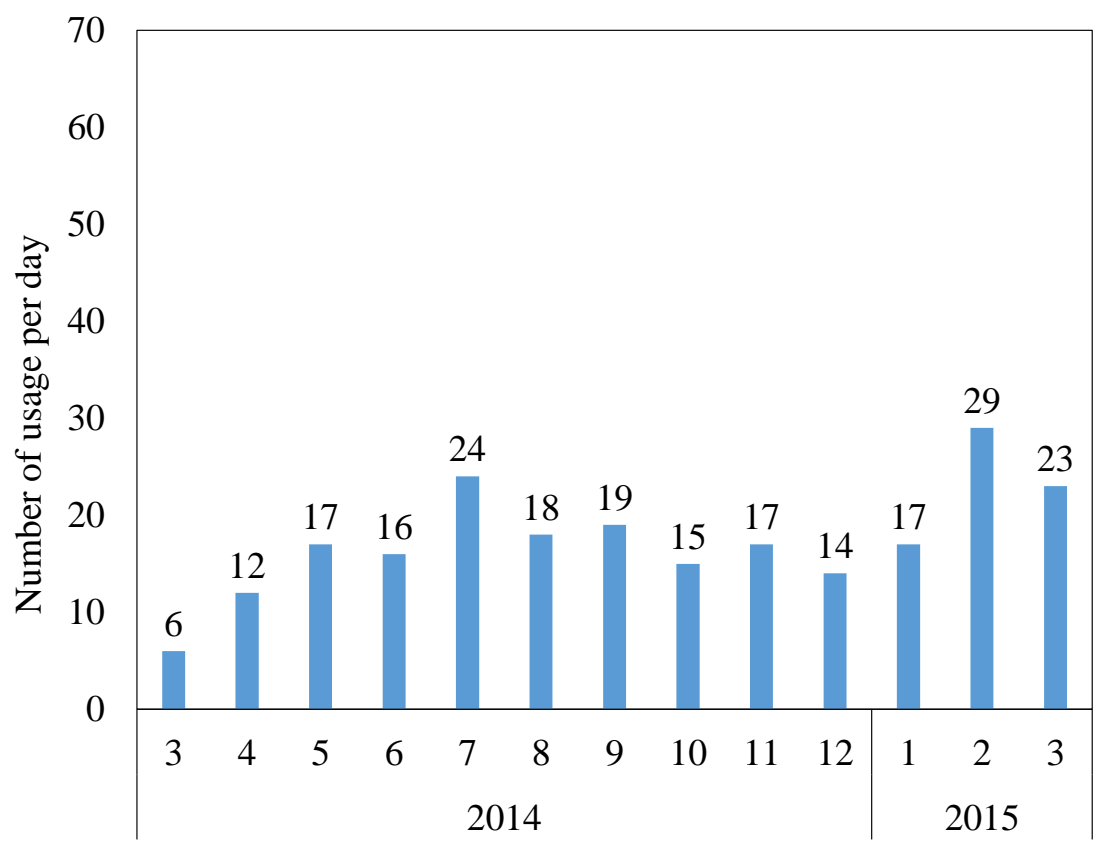

Figure 4. Average Daily Usage (Academic Holiday)

We observe from the OD matrix in Table 2 that many trips are round trips where users park their shared bicycle at the same station from where they started their trip. This 
suggests that users did not use COGOO for reaching university facilities such as lecture rooms at the other side of the campus but instead for errands. Table 3 shows the reduced OD matrix with origins and destinations aggregated by campus area (see Figure 1). The matrix highlights that COGOO is for the majority of trips not used for reaching different areas of the campus. Following up from this result, we divided trips into three groups. Firstly, Type A are trips where the origin port and the destination are the same, Type B where the user returned the bicycle to a docking port in the same campus area and Type $\mathrm{C}$ where the user returned the bicycle in a different campus area.

Table 2. OD Matrix (location of parking places shown in Figure 1)

\begin{tabular}{|c|c|c|c|c|c|c|c|c|c|c|}
\hline & N1 & N2 & C1 & C2 & C3 & C4 & S1 & S2 & M1 & M2 \\
\hline N1 & 778 & 148 & 91 & 343 & 106 & 7 & 47 & 136 & 27 & 83 \\
\hline N2 & 166 & 594 & 52 & 286 & 72 & 22 & 89 & 407 & 37 & 57 \\
\hline $\mathrm{C} 1$ & 75 & 87 & 562 & 188 & 81 & 12 & 76 & 156 & 5 & 14 \\
\hline $\mathrm{C} 2$ & 355 & 246 & 217 & 1955 & 209 & 12 & 173 & 552 & 26 & 102 \\
\hline $\mathrm{C} 3$ & 98 & 68 & 104 & 191 & 364 & 4 & 56 & 152 & 4 & 37 \\
\hline $\mathrm{C} 4$ & 12 & 14 & 13 & 18 & 5 & 20 & 3 & 8 & 3 & 16 \\
\hline S1 & 52 & 93 & 54 & 213 & 52 & 6 & 236 & 126 & 1 & 30 \\
\hline S2 & 111 & 449 & 138 & 557 & 152 & 11 & 118 & 902 & 7 & 68 \\
\hline M1 & 25 & 43 & 7 & 19 & 6 & 4 & 3 & 0 & 44 & 36 \\
\hline M2 & 101 & 32 & 17 & 105 & 24 & 16 & 29 & 70 & 35 & 187 \\
\hline
\end{tabular}

Number of usage of each OD pairs (all data)

Table 3. OD Matrix by Campus Area see Figure 1

\begin{tabular}{|c|c|c|c|c|}
\hline & $\mathrm{N}$ & $\mathrm{C}$ & $\mathrm{S}$ & $\mathrm{M}$ \\
\hline $\mathrm{N}$ & 1686 & 979 & 679 & 204 \\
\hline $\mathrm{C}$ & 955 & 3955 & 1176 & 207 \\
\hline $\mathrm{S}$ & 705 & 1183 & 1382 & 106 \\
\hline $\mathrm{M}$ & 201 & 198 & 102 & 302 \\
\hline
\end{tabular}

To obtain some indication for what purposes COGOO was used we calculated time of rental period for each usage type as shown in Figure 5. We observe no large difference between usage time for trips of Type A and B but of show time of usage. These imply that Type A and B are almost same whereas Type $C$ trips are much shorter. This is further evidence that trips ending in the same zone are likely errands outside of campus. 


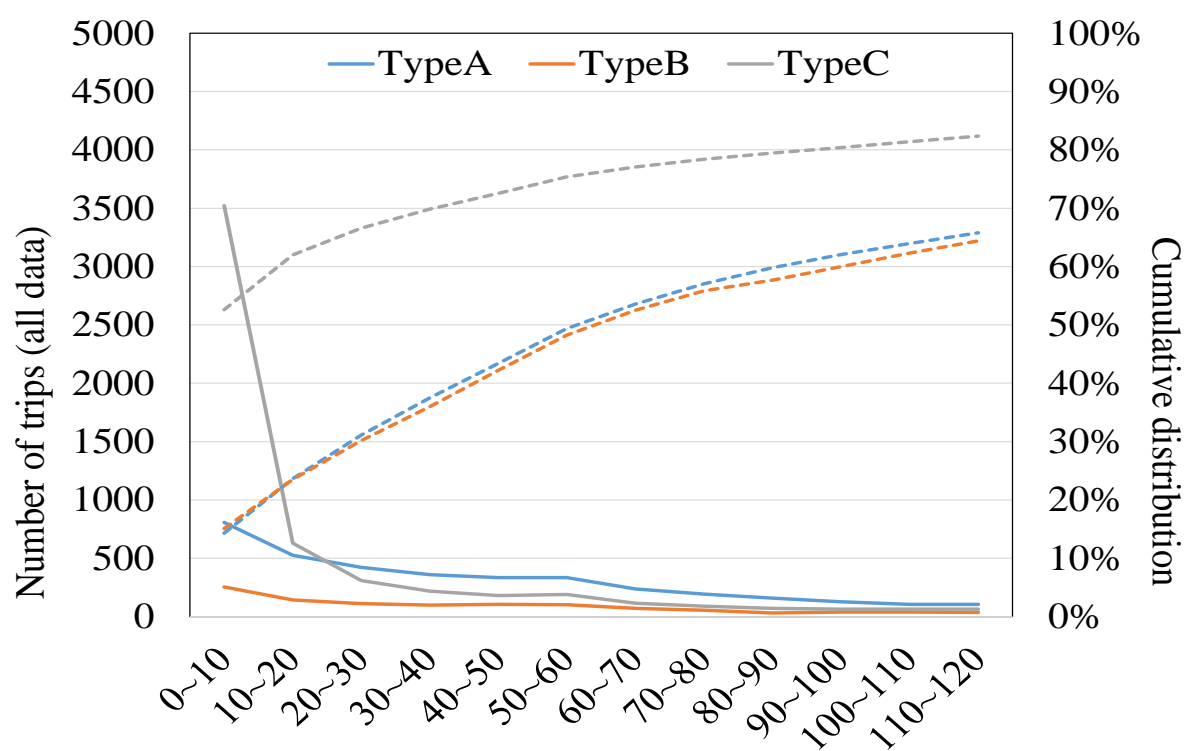

Time of usage (minutes)

Figure 5. Time Duration of Trips

(Type A: $O$ port $=\mathrm{D}$ port; $\mathrm{B}: \mathrm{O}$ area $=\mathrm{D}$ area; $\mathrm{C}: \mathrm{O}$ and $\mathrm{D}$ area differ)

In the following, we combine trips of Type A and B and just distinguish these from Type C. We refer to trips of Type A or B as round trips and Type $C$ as one-way trip. The overall illegal usage rate, that is using the bicycle for longer than 1 hour is $38.3 \%$. We observe though a difference between round trips and one-way trips. For round trips, the percentage is $50.8 \%$, whereas the rate for one-way trips is only $24.6 \%$. Figure 6 further shows the distribution by time of day. We observe that, as expected, some users often used COGOO at the time when classes start or finish. Particularly at lunchtime round trips proportion is high, indicating that possibly, some users used COGOO to visit restaurants outside campus. Considering this and the high illegal usage rate, revisions of the rule may be required in that 1 hour is often not sufficient for users.

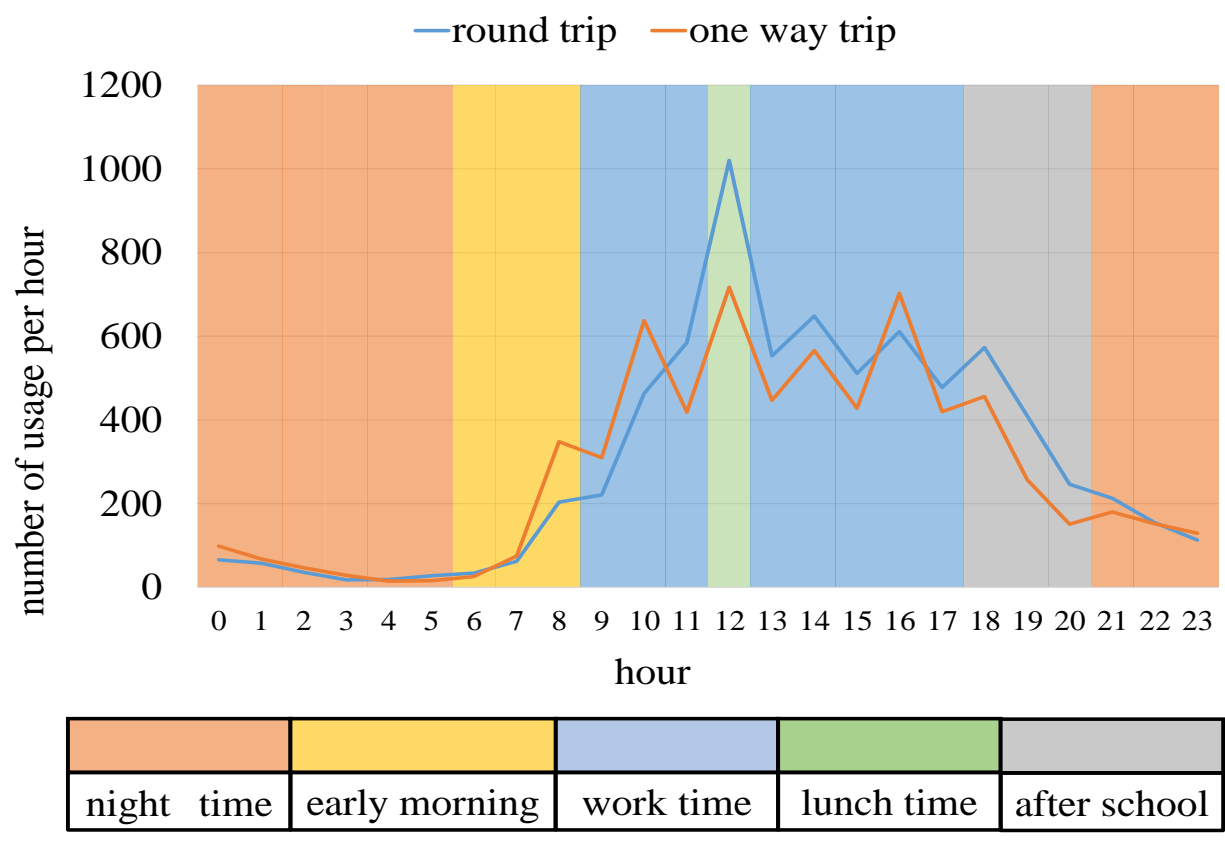

Figure 6. Time Zone of Usage for each Pattern 


\section{Cluster Analysis}

To understand more about the different usage types, we classify COGOO members according to their usage patterns. To do so, we selected following behavioral variables: type of trip, illegal usage (exceeding allowed rental period), daytime of usage and number of rentals (Table 4).

Table 4. Variables used for Clustering

\begin{tabular}{|c|l|}
\hline Illegal usage rate & Proportion of usage more than 1 hour (the max allowed rental period) \\
\hline Commuting time rate & Proportion of usage 6 - 9am \\
\hline Work time rate & Proportion of usage 9-11am and 1-6pm \\
\hline Lunch time rate & Proportion of usage 12n-1pm \\
\hline After school rate & Proportion of usage 6-9pm \\
\hline Midnight rate & Proportion of usage 9pm-6am \\
\hline Round rate & Proportion of round trips (pick-up = drop-off location) \\
\hline Scaled usage frequency * & (average usage) $/ 16 * *$ \\
* Variable not used for cluster analysis. \\
** Since the largest average usage frequency in a cluster is 15.8, this creates a variable in the range of $0-1$.
\end{tabular}

We tested models with 2 15 clusters. Based on the minimum BIC value we concluded that six clusters is most appropriate. Figure 7 shows the average of each cluster variables and the name we gave to each cluster based on this spider diagram. Cluster 1 contains many users who use COGOO during working times and obey rules; we call this cluster accordingly "work-time users". Cluster 2 members, "night-time users", contains predominantly those using COGOO at late night. Their average usage per month is the highest among the users. Cluster 3 in contrast includes those who often use COGOO after-school. As they make many round trips but also use COGOO during school hours, we call this cluster "multi-purpose after-school users". Also the main characteristic of Clusters 4 ("early morning users") and 5 ("lunch time users") is the usage time. Cluster 6 instead contains users similar to Custer 1 in terms of usage hours, but these users often do not keep the time limitation and we refer to this group as "rule-breaking users".

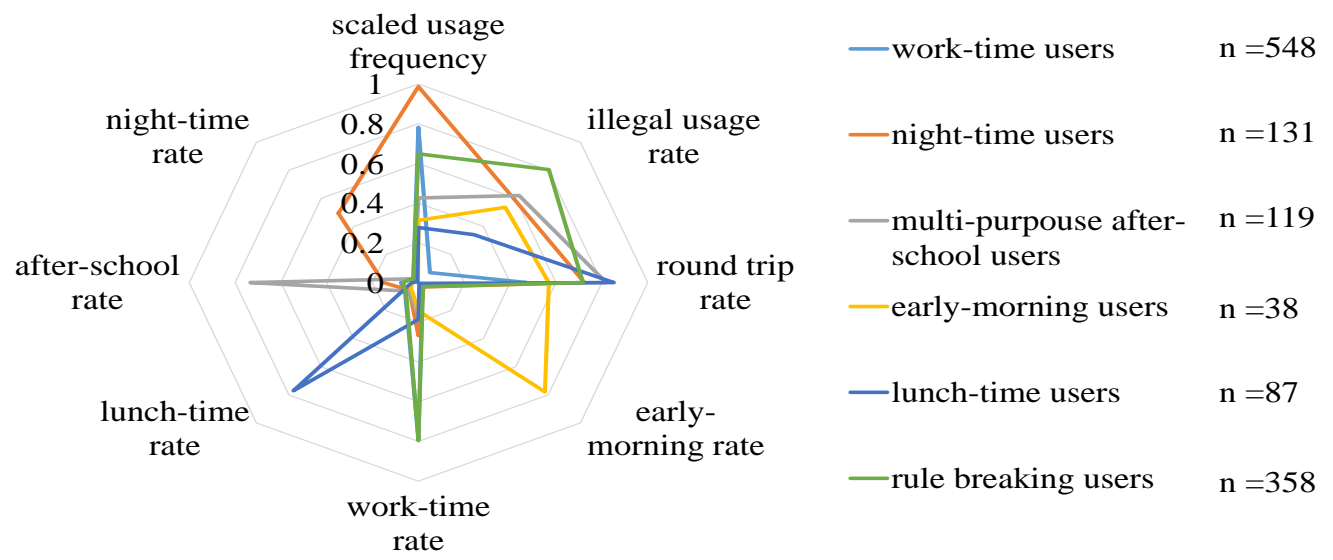

Figure 7. Cluster Analysis Results

We can now also compare our behavioral clusters with other limited information we have about the users such as whether they are staff, under- or postgraduate student as well as whether they have withdrawn from the scheme. Figure 8 shows that users classified as "rule breaking users" have a high rate of withdrawing. From Figure 7 we observe that this cluster has the second highest number of usage. Further, "night-time users" have the highest level of scaled usage frequency as well as the highest rate of withdrawing. This therefore shows the vulnerability of the system in that users are fluctuating. 


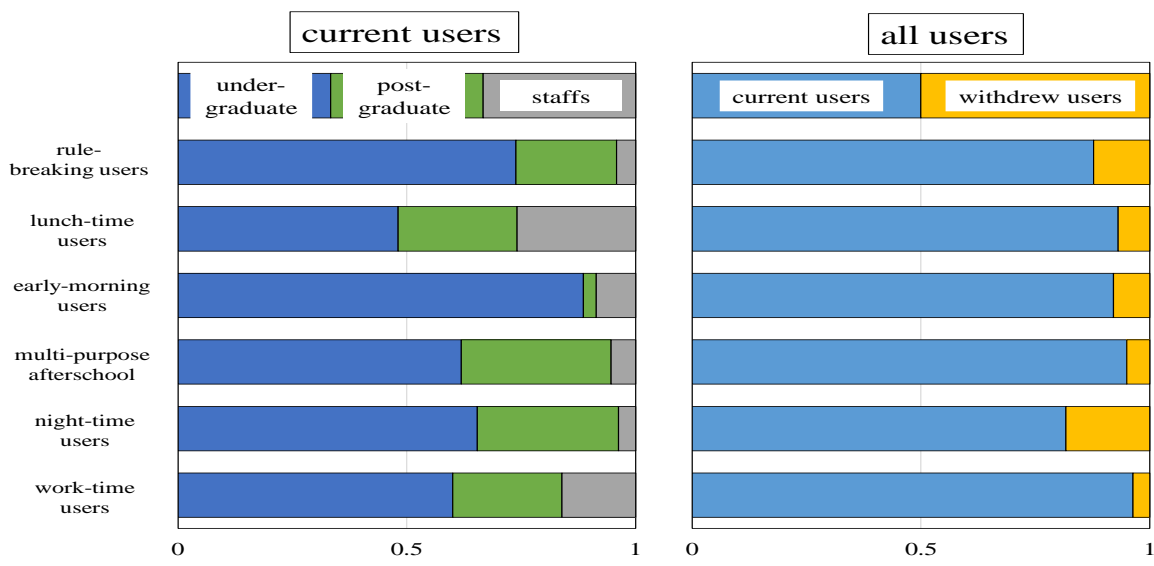

Figure 8. Cluster Characteristics

\section{Survey Analysis}

\subsection{Questionnaire Overview}

From the analysis presented in previous section we cannot know more about the trip purposes nor about reasons for non-users not to use COGOO. We conducted a survey analysis among both users and non-users. We created a web-based questionnaire and recruited respondents among students as well as staffs by distributing flyers as well as directly sending the web-link to COGOO users. The implementation period was from January 8 to January 22, 2016. As a result, we obtained 368 users' and 113 non-users' responses (see Table 5). The main contents of the questionnaire concerned their attitudes towards cycling, their awareness of COGOO and questions regarding their activities at university. We posed questions about attitudinal and awareness on a 5-point Likert scale. The following section describes our tests for differences among users and non-users. In 6.3 we then describe the two types of regression analysis that we conducted based on these data.

Table 5. Summary of Questionnaire

\begin{tabular}{|c|c|c|}
\hline & users & not-users \\
\hline date & $2016 / 1 / 8 \sim 15$ & $2016 / 1 / 18 \sim 22$ \\
\hline way & web questionaire \\
\hline number & 368 & 113 \\
\hline \multirow{3}{*}{$\begin{array}{c}\text { question } \\
\text { contents }\end{array}$} & \multicolumn{2}{|c|}{ about sense of resistance } \\
\cline { 2 - 3 } & \multicolumn{2}{|c|}{ about environment problems } \\
\cline { 2 - 3 } & \multicolumn{2}{|c|}{ about your life in college } \\
\cline { 2 - 3 }
\end{tabular}

\subsection{Difference of Awareness between Users and Not Users}

To obtain reliable constructs used for comparison between different groups, we conducted firstly a Cronbach' alpha-reliability with questionnaire items measuring the same construct (Table 6). Following general convention, we consider values above 0.7 as acceptable, with values near 1 being desired. The reliability of our second construct "innovativeness" is 0.85 and hence acceptable so that we can construct a reliable latent construct based on the mean of the variables. For the five questions on obeying rules, we 
obtained an alpha-value of 0.67 which we consider not acceptable. We tested for dropping specific items but this does not significantly improve the reliability of the "neglecting rules" construct. The result suggests that finding a set of questions that clearly define an attitude of ignorance to rules is difficult. In Table 6, we hence test for differences among users and non-users for each item separately. For the two questions relating to environmental concern we also decided against using a latent measure and instead use the two items separately in Table 6.

To understand which test we can choose for our comparison between users and nonusers, we firstly checked whether our data follow a normal distribution. We applied the Kolmogorov-Smirnov test which suggests for all items that our data are statistically significantly different to a normal distribution. We therefore utilized the non-parametric Mann-Whitney $U$ test as an alternative to t-tests to understand differences between users and non-users.

Table 6. Cronbach Alpha Reliability

\begin{tabular}{|c|c|c|}
\hline & questions & $\alpha$ \\
\hline \multirow{5}{*}{ rules } & I don't have to obey rules which I disagree with. & \multirow{5}{*}{0.67} \\
\hline & I don't care to reieve light punishments. & \\
\hline & I don't have to obey rules which anyone don't obey. & \\
\hline & I can neglect rules unless I make someone in trouble. & \\
\hline & I can leave my bicycle unless I make someone in trouble & \\
\hline \multirow{8}{*}{$\begin{array}{l}\text { innovativeness } \\
\text { (inverse scale) }\end{array}$} & I am generally cautious about accepting new ideas. & \multirow{8}{*}{0.85} \\
\hline & I am suspicious of new inventions and new ways of thinking. & \\
\hline & $\begin{array}{l}\text { I rarely trust new ideas until I can see } \\
\text { whether the vast majority of people around me accept them. }\end{array}$ & \\
\hline & $\begin{array}{l}\text { I am aware that I am usually one of the last people } \\
\text { in my group to accept something new. }\end{array}$ & \\
\hline & $\begin{array}{l}\text { I am reluctant about adopting new ways of doing things } \\
\text { until I see them working for people around me. }\end{array}$ & \\
\hline & I tend to feel that the old way of living and doing things is the best way. & \\
\hline & I must see other people using new innovations before I will consider them. & \\
\hline & I am receptive to new ideas. & \\
\hline
\end{tabular}

Table 7. Result of Mann-Whitney U test

\begin{tabular}{c|l|c|l|l}
\hline \multicolumn{2}{c}{} & users & not-users & $\mathrm{Z}$ value \\
\hline $\begin{array}{c}\text { innovativeness } \\
\text { (invers scale) }\end{array}$ & level of resistance to new things & 2.646 & 2.854 & $-2.208^{* *}$ \\
\hline \multirow{4}{*}{ rules } & I don't have to obey rules which I disagree with. & 2.035 & 2.053 & -0.427 \\
& I don't care to reieve light punishments. & 2.409 & 2.386 & -0.327 \\
& I don't have to obey rules which anyone don't obey. & 2.439 & 2.526 & -0.567 \\
& I can neglect rules unless I make someone in trouble. & 2.610 & 2.465 & -1.037 \\
\cline { 2 - 6 } & I can leave my bicycle unless I get someone in trouble. & 2.480 & 3.772 & $-9.328^{* * *}$ \\
\hline \multirow{2}{*}{ environment } & I am interested in environmental problems. & 3.225 & 3.465 & $-1.723^{*}$ \\
\cline { 2 - 6 } & I do something to protect the environment. & 3.160 & 3.114 & -0.500 \\
\hline
\end{tabular}

level of significance $* * * 1 \% * * 5 \% * 10 \%$ 
Table 7 shows the result of the U tests. We find that COGOO users tend to be more innovative or "have less resistance to new things". Our explanation is that at least for some users the fact that they perceive bicycle sharing as a new mode of transport has encouraged them to sign up. In the longer run, this "thrill of being new" will reduce and some of these users might possibly drop out. The implication of this result is though also that highlighting the fact that the scheme is new and innovative can help attracting additional users.

We also find that non-users do not care about leaving bicycles at places where they might disturb others. This suggests that motivating the students or staff who cause a problem to the campus environment to use COGOO is difficult. More generally, we suggest that improving resistance to leaving bicycles at non-appropriate places appears to be important. In line with this, we expected that users might have in general more environmental consciousness, not only because of cycling being an active travel mode but also because illegal parked bicycles worsen the road and landscape environment which might also be connected to general environmental consciousness. However, the analysis indicates a weakly significant opposite sign. We suggest this indicates that the most significant reason of using COGOO is the convenience of it and one might suspect that those who care only about convenience care less about campus problems.

\subsection{Binary Logit Model to Explain Difference between Users and Not Users}

To further control for other factors, we performed a binary logistic regression analysis. After initial tests to filter out highly correlated explanatory variables, the left side of Table 8 shows our final model with the dependent variable COGOO user coded as one and nonuser as zero. We find that those who stay in college late or overnight, who come to school by motorbike and who generally like to ride a bicycle use COGOO more. These results are in line with our expectations. In particular, it shows that COGOO supports students with an active campus life, such as those committed to their club activities as well as those who study late and might then use COGOO for some errands in the campus area. Furthermore, students who live at home and not in nearby dormitories mainly used COGOO, which is also understandable, as those living nearby are more likely to commute by their own bicycle. Our previously discussed results regarding consciousness of leaving bicycles parked at the university and interest in environmental problems are confirmed, even controlling for these factors. We do find though that innovativeness does not appear to be significant anymore. We suggest this means that life style has a stronger influence than consciousness.

\subsection{Ordered Logit Model to Explain Usage Frequency}

We further performed an ordered logistic regression analysis with the same explanatory variables to understand the difference between high frequency, low frequency and nonusers (Table 8, right column). Most of the results for the binary logistics model are confirmed. Not surprisingly, variables connected to commuting behavior become more significant, in that now "I come to university by bus" is positively significant and "I come to school by bicycle" is negatively significant. We can explain the difference in that these students also sign up for COGOO but then they do not use it very much. We further find that innovativeness is now significant, suggesting hence that those who are curious about COGOO also end up using it more, or possibly even start relying on the service. 


\section{Table 8. Result of Regression Analysis}

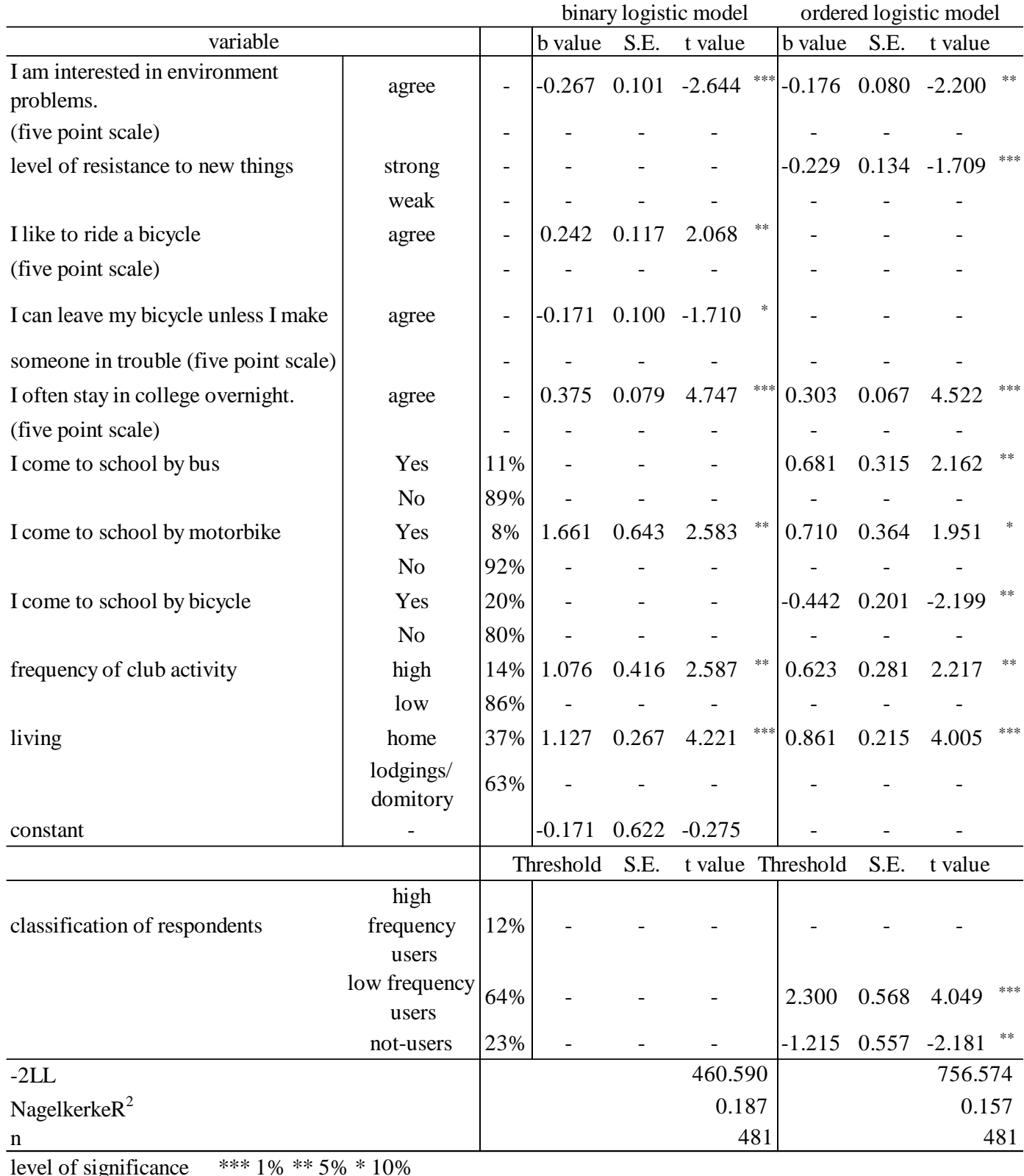

\section{Conclusions}

In this paper, we discussed problems of university cycle sharing and tried to explain how it is used and what users are attracted by it. We firstly observed that the main usage is not for access of university facilities. We observed that the majority of trips are round trips where users dock the bicycle at the same station (or at least very near the same station) from where they left, possibly to go shopping at nearby convenience stores or to go for lunch at restaurants around campus. Whether this will be the case also in other cities will of course depend on the location of the campus. The main campus of Kyoto University is within the city center close to a number of shops and restaurants. Our cluster and descriptive analysis further suggests that a number of students use the scheme at night, possibly again for errands though maybe also to reach some of the location where they have sports and other type of club activities. In general, we can fairly clearly 
distinguish different user types with "lunchtime" and "late night" users being an important group.

We further conclude from our survey analysis, and in line with our suggestions from the usage data analysis, that convenience and on- as well as off-campus accessibility are the most significant determinants of signing up for COGOO as users are more likely to be students involved in club activities and/or stay overnight at university. An argument pro shared cycle schemes is therefore that it can support an active campus life.

Our general implication and suggestion is therefore that planners should be clear as to what cycle sharing schemes are likely to be used. If safe movements of students at night times and integration of the campus with the surrounding area are objectives, campus cycle sharing schemes might well be an option. A main objective, from a planning point of view, in the Kyoto case was though to reduce the number of privately owned bicycles parked around the campus. To understand whether campus bicycle schemes are enough for students and staff who commute by public transport not to leave a bicycle permanently on campus is though still unclear and requires a very targeted survey.

The objective of our survey was rather to more generally understand attitudinal and other differences between those who signed up for COGOO and those who did not. We found that users' rate statistically significant higher on an innovativeness scale, suggesting that the scheme attracts in general those who are more likely open for new ideas. This also reflects the findings of [20] who discuss the importance of innovativeness for uptake of a new form of transport. Turning this around, this finding might suggest that highlighting "shared bicycles are introduced as a new transport opportunity" can attract users.

Finally, and on a first glance surprising, we find that COGOO users appear to care less for the environment. Our explanation is that COGOO users also tend to be more likely car and motorcycle users. Therefore, one might even consider that this can be a possible argument against introducing campus cycle schemes as the improved on-campus accessibility primarily supports those not coming by their own bicycle to campus. Whether this effect can be significant we cannot answer though with our data and we suggest it remains a topic of further research.

\section{References}

[1] T. Abe and M. Kawashima, "Research on Construction and the Management Technique of Community Cycle System", Architectural Institute of Japan (Kanto), F-1, (2003), pp, 131-132.

[2] A. Komukae, S. Fuji and J. D. Schmöcker, "Survey on bicycle image and unlawful behavior in Kyoto and London", Proceedings of the 45th Research Meeting on Civil Engineering Planning, (2012), June 23.

[3] J. Pucher and R. Buehler, "Cycling for everyone: lessons from Europe", Transportation Research Record: Journal of the transportation research board, no. 2074, (2008), pp. 58-65.

[4] J. Pucher, "Bicycling boom in Germany: a revival engineered by public policy", Transportation Quarterly, vol. 51, no. 4, (1997), pp. 31-46.

[5] A. Goodman, J. Green and J. Woodcock, "The role of bicycle sharing systems in normalising the image of cycling: An observational study of London cyclists", Journal of transport \& health, vol. 1, no. 1, (2013), pp. 5-8.

[6] J. Schoner, R. A. Harrison and X. Wang, "Sharing to grow: Economic activity associated with Nice Ride Bike share stations", Hubert H. Humphrey School of Public Affairs. Retrieved from the University of Minnesota Digital Conservancy, (2012) August 31.

[7] E. Murphy and J. Usher, "The role of bicycle-sharing in the city: Analysis of the Irish experience", International Journal of Sustainable Transportation, vol. 9, no. 2, (2015), pp. 116-125.

[8] D. Zhang, J. D. Schmöcker and X. Yang, "Perceived Service Quality and Its Influence on Bike Sharing System Usage: Case Study from Shanghai", Proceedings of the 47th Research Meeting on Civil Engineering Planning, (2013) June 1-2.

[9] E. Fishman, "Bikeshare: A review of recent literature", Transport Reviews, vol. 36, no. 1, (2016), pp. 92-113.

[10] S. Shaheen, S. Guzman and H. Zhang, "Bikesharing in Europe, the Americas, and Asia: past, present, and future", Transportation Research Record: Journal of the Transportation Research Board, no. 2143, (2010), pp. 159-167. 
[11] I. Frade and A. Ribeiro, "Bicycle sharing systems demand", Procedia-Social and Behavioral Sciences, vol. 111, (2014), pp. 518-527.

[12] T. Doi., "Study on the policy against illegally parked bicycles in transportation planning in cooperation with Machizukuri", Proceeding of Kobe International University economic and management review, vol. 30, no. 1, (2010), pp. 33-62.

[13] H. Ieda and H. Kato, "A Model of Bicycle-User's Bahavior in Access-Transport to Railway Station", City planning review. Special issue, Papers on city planning, vol. 30, (1995), pp. 643-648.

[14] H. Abe, M. Awai, K. Tsuji and T. Yasui, "The Present Situation of Illegally Parked Bicycles and the Opinion of Bicycle Users in the Center of Okayama City", Japan Society of Civil Engineers, vol. 19, (2002), pp. 603-611.

[15] T. Hatori, S. Mikiya and S. Fuji, "An Examination on the Effects of Measures for Reducing the Illegal Bicycle Parking by Psychological Strategy: A Case Study on Toritsu-daigaku Station, Tokyu Corporation", Japan Society of Civil Engineers, vol. 26, no. 4, (2009), pp. 797-805.

[16] A. Makino, Y. Yamashita and N. Adachi, "Design construction at the citizens participation type Nagoya version community cycle system", Proceedings of the annual conference of JSSD, vol. 56, (2009), pp. 20.

[17] H. Kaminokado, F. Nakamura and S. Tanaka, "A Study on the Role and Effect Which Bike Sharing in a University", Proceedings of the 50th Research Meeting on Civil Engineering Planning, (2014), pp. 43.

[18] T. Yamamoto, A. Marui and M. Yokota, "Social experiment of rental bicycle on Ito campus Kyushu University -Examination of a sustainable social business model", Architectural Institute of Japan (Tokai), (2012), pp. 823-826.

[19] Z. Cen and J. D. Schmöcker, "A Markovian model of user adaptation with case study of a shared bicycle", Transportmetrica B, (In press).

[20] Y.-T. Li and J.-D. Schmöcker, "The Impact of Attitudes and Perceptions on High Speed Rail Usage Uptake in Taiwan and the Shanghai Area", Asian Transport Studies, vol. 4, no. 3, (2017), pp. 601-620. 